\title{
Elasticidade Renda e Elasticidade Preço das Exportações e das Importações de Produtos Industrializados no Brasil (2003-2010): Uma Avaliação Utilizando Dados em Painel ${ }^{*}$
}

\author{
Carlos Tadao Kawamoto ${ }^{1}$ \\ Breno Lobo Santana ${ }^{2}$ \\ Hélio Fonseca ${ }^{3}$
}

\begin{abstract}
Resumo: O presente trabalho tem como objetivo estimar as elasticidades renda e preço das exportações e das importações de produtos industrializados no Brasil para o período compreendido entre os anos 2003 e 2010. Foram estimados modelos estáticos e dinâmicos para as exportações e para as importações, utilizando dados desagregados por categoria da indústria de transformação. A principal contribuição do trabalho recai nas elasticidades estimadas por meio do estimador para correção de viés em painéis dinâmicos com pequeno número de indivíduos proposto por Bruno (2004, 2005). De maneira geral, os resultados apontam para uma resposta mais aguda, tanto de exportações quanto de importações, a variações na renda que a variações nos preços. Além disso, encontram-se resultados contra-intuitivos sobre a influência da taxa de câmbio sobre a quantidade de exportações. Ratifica-se, ainda, a relevância do componente dinâmico nos volumes de bens industriais transacionados com o resto do mundo.
\end{abstract}

Palavras-chave: comércio exterior; exportações; importações; elasticidade renda; elasticidade preço

JEL: F1, F14, C23

\footnotetext{
* As opiniões expressas neste trabalho são exclusivamente dos autores e não refletem a visão do Banco Central do Brasil ou da Anatel

1 Analista do Banco Central do Brasil. Mestre em Economia (UFSC). E-mail: ctkawamoto@gvmail.br

2 Analista do Banco Central do Brasil. Doutorando em Economia (UnB). E-mail: brenolobo@ig.com.br

3 Especialista em Regulação de Serviços Públicos de Telecomunicações - Anatel. Doutorando em Economia (UnB). E-mail: hmmfonseca@gmail.com
} 


\title{
Income Elasticity and Price Elasticity of Exports and Imports of Manufactured Goods in Brazil (2003-2010): An Assessment Using Panel Data
}

\begin{abstract}
This study aims to estimate the income and price elasticities of exports and imports of industrial products in Brazil for the period between 2003 and 2010. Static and dynamic models for exports and imports were estimated using a dataset disaggregated by categories of the manufacturing industry. The main contribution of this paper lies in the elasticities estimated by the bias-corrected LSDV estimator for dynamic panels with a small number of individuals proposed by Bruno (2004, 2005). Overall, the results point to a higher effect over both exports and imports of the variations in income than to changes in prices. Moreover, counterintuitive results on the influence of the exchange rate on the amount of exports are found. The results also confirm the relevance of the dynamic component in the volume of industrial goods traded abroad.
\end{abstract}

Key-words: international trade; exports; imports; income elasticity; price elasticity

JEL: F1, F14, C23

\section{Introdução}

A estimação das elasticidades renda e preço das importações e das exportações é importante tópico da literatura empírica de economia internacional, com resultados utilizados em projeções de comércio exterior e em análises de política econômica, dentre outras aplicações. Como exemplo, pode-se, através da elasticidade preço, avaliar de que maneira uma mudança nos preços relativos afeta o saldo comercial de um país. Já a elasticidade renda, caso a participação do saldo de bens na conta corrente de uma economia seja relevante, auxilia na verificação da existência de restrições ao crescimento impostas pelas transações com o resto do mundo, em modelos à la Thirlwall (1979).

A literatura empírica não se mostra consensual sobre os resultados das referidas elasticidades, apesar da extensão de publicações sobre o tema (e.g., Zini Jr. 1988; Castro \& Cavalcanti 1998; Fullerton et al. 1999; Campos \& Arienti 2002; Skiendziel 2008; Santos et al. 2009). Por exemplo, a elasticidade preço das vendas agregadas de bens brasileiros para o resto do mundo situa-se entre $-0,10$ e $-1,51$. Para as importações, os valores da elasticidade renda oscilam entre $+0,42$ e $+2,33$. Dada a elevada amplitude desses números, esforços adicionais no sentido de utilizar novas técnicas econométricas para estimar essas elasticidades tornam-se relevantes. 
No entanto, poucos esforços têm sido direcionados no sentido de estimar elasticidades setoriais. As elasticidades estimadas nos trabalhos supracitados, e nessa literatura em geral, indicam apenas o efeito médio, que seria constante entre todos os setores da economia. Todavia, dada a sua heterogeneidade, deve-se esperar que modificações na renda e nos preços relativos tenham diferentes efeitos sobre as quantidades exportadas e importadas nos diversos setores da economia.

O objetivo desse trabalho é estimar as elasticidades renda e preço das exportações e das importações de produtos industrializados. Essa opção se justifica por esses produtos possuírem maior valor agregado e por incorporarem mais intensidade tecnológica. Nesse sentido, é importante conhecer os fatores que explicam a evolução do comércio exterior nesse setor. Utilizaram-se dados mensais para os anos de 2003 a 2010 da indústria de transformação brasileira. Os dados foram desagregados entre as vinte categorias que compõem a indústria de transformação, de acordo com a Classificação Nacional de Atividade Econômica (CNAE) do IBGE. Foram utilizados sete diferentes estimadores para avaliar essas elasticidades. Em geral, os resultados apontam para uma resposta mais aguda, tanto de exportações quanto de importações, a variações na renda que a variações nos preços. Além disso, encontram-se resultados contra-intuitivos sobre a influência da taxa de câmbio sobre a quantidade de exportações. Ratifica-se, ainda, a relevância do componente dinâmico nos volumes de bens industriais transacionados com o resto do mundo.

Para alcançar seus objetivos, o trabalho foi dividido em quatro seções, além desta introdução. A segunda seção faz uma breve referência às abordagens teórica e empírica empregadas em estudos de natureza semelhante. A terceira seção destaca a importância da indústria de transformação nos totais das transações comerciais com o resto do mundo no período investigado. A quarta seção apresenta os dados utilizados e a metodologia econométrica adotada. Os resultados são expostos na quinta seção, seguidos pelas considerações finais.

\section{Breve revisão da literatura}

A teoria de comércio internacional pode ser segmentada em três grandes grupos $^{1}$. O primeiro é o neoclássico, com origem em Ricardo e a sua teoria das vantagens comparativas, sendo base da abordagem contemporânea de Heckscher-Ohlin, em que os fluxos de comércio são determinados pelos preços relativos entre os países, de acordo com a dotação dos fatores existentes nas economias. O nível de emprego é assumido como fixo e o produto se encontra na fronteira de produção. O segundo grupo está baseado na teoria Keynesiana. Thirlwall (1979), por exemplo, apresenta as condições em que o crescimento de uma economia estaria limitado pelos recursos do exterior, captados basicamente, em sua formulação original, pelo comércio 1 Baseado em Hong (1999) 
de bens. Em seu modelo, os preços relativos são tomados como constantes, sendo a elasticidade renda da demanda por importações e a taxa de crescimento das exportações os determinantes do equilíbrio nas transações com o resto do mundo. O terceiro grupo é chamado de nova teoria de comércio. Tomando como hipótese estruturas de mercado não competitivas e setores com retornos crescentes, essa abordagem introduz a ideia de que economias de escala e diferenciação de produto são elementos relevantes do comércio internacional. Por essa teoria, a influência da renda sobre o comércio não pode ser exclusivamente atribuída ao poder de compra, uma vez que a renda também é vista como proxy de escala. Se por um lado uma elevação na renda pode incrementar a demanda por importados, também indica crescimento da indústria local, que com maior escala produz mais eficientemente e reduz a dependência por bens do exterior.

No campo empírico, as estimações das elasticidades de exportação e de importação com dados nacionais agregados são baseadas em um referencial teórico de economia pequena ou grande. No primeiro referencial, assume-se que o país investigado não influencia os preços internacionais. Assim, no caso das exportações, a elasticidade preço da demanda pelos produtos do país em análise é considerada infinita e somente a elasticidade preço da oferta de exportação é investigada. No caso das importações, considera-se a elasticidade preço da oferta como infinita e avalia-se apenas a elasticidade da demanda do país investigado. Para uma vasta gama de países e produtos esse modelo é razoável. Mesmo em casos de grandes produtores (exportadores) ou consumidores (importadores) em que o modelo de economia grande se tornaria conveniente, a existência de custos de transporte não desprezível para muitos produtos invalida a lei do preço único, tornando a aplicação do modelo de economia pequena adequada.

A existência de uma participação elevada do comércio exterior de um determinado país sobre a produção ou sobre o consumo global sugere a restrição da análise aos modelos para grandes economias. Esses podem ser divididos em dois grandes blocos. Nos modelos de bens substitutos imperfeitos, o ajuste se dá nas quantidades, sendo a demanda por importados de um país igual à soma das ofertas de importados do resto do mundo. O mesmo se aplica às exportações. Nesses casos, técnicas de equações simultâneas são usualmente empregadas, avaliando oferta e demanda separadamente. No modelo de substitutos perfeitos ${ }^{2}$, a lei de preço único é válida e os preços domésticos e internacionais convergem. Para dados agregados, essa situação dificilmente é observada, por isso as análises de produtos específicos são dominantes, baseadas amplamente em métodos de séries temporais.

O modelo ideal ou correto a ser empregado varia com o propósito da investigação. Como em qualquer estudo empírico, a disponibilidade de dados deve ser observada, principalmente aqueles relativos ao volume do consumo (im-

2 Nos modelos de substitutos perfeitos usualmente se assume que os custos de transporte são baixos e há homogeneidade entre os bens. 
portação) e da produção (exportação) do país ou região em análise. O fato de o comércio exterior da maioria dos países não impactar nos preços mundiais torna o modelo de países pequenos uma referência amplamente utilizada. Para o caso brasileiro, foco deste trabalho, tem-se que as importações são pulverizadas sobre uma ampla gama de diferentes produtos, permitindo a adoção do modelo de país pequeno. As vendas ao exterior, por outro lado, são relativamente concentradas em poucos produtos, com destaque para minério de ferro, soja, açúcar e café, cujas exportadoras brasileiras possuem potencialmente algum "poder de mercado" global ${ }^{3}$. Isso torna relevante a investigação do alinhamento de longo prazo entre os preços nos diferentes mercados. Uma refutação da cointegração dos preços sugere a adoção do modelo de bens substitutos imperfeitos, usualmente empregado na literatura. Para o caso deste trabalho, porém, em que o foco se situa nos produtos da indústria de transformação, a concentração pode ser considerada pequena, com reduzida participação dos produtos nacionais sobre seus respectivos mercados mundiais.

Diversos trabalhos estimam as elasticidades preço e renda das exportações e das importações para o Brasil em diferentes períodos. Todavia, não se tem conhecimento de trabalhos que façam esse exercício com dados desagregados por setor de atividade econômica. Nesse sentido, o foco será apresentar a literatura que estima as elasticidades com dados agregados, que servirão como benchmark para a comparação com as elasticidades da indústria de transformação.

Apesar de ser teoricamente mais razoável empregar os quanta transacionados como variável dependente em avaliações econométricas, alguns autores adotam os valores das exportações e das importações. Entre eles podem ser citados Castro e Cavalcanti (1998), Fligenspan (2008) e Santos et al. (2009).

Castro e Cavalcanti (1998) utilizaram valores das exportações e das importações anuais deflacionados pelos preços nos EUA, entre 1955 e 1995. O PIB deflacionado e a taxa de câmbio real são empregados, respectivamente, como proxies do nível de atividade e dos preços relativos na equação de importação. Para as exportações, foram empregados o índice das importações mundiais do FMI e a taxa de utilização da capacidade produtiva, construída pela fração entre o PIB e o produto potencial, como proxies da renda mundial e do nível de atividade doméstica, respectivamente. Além dos testes realizados para dados agregados de exportação e de importação, os autores também avaliaram as exportações de maneira desagregada em bens manufaturados, semimanufaturados e básicos; e as importações em bens de capital, intermediários e de consumo. Seus resultados apontam que o controle de déficits comerciais pelo câmbio tende a ser mais eficiente que o controle pela demanda agregada.

Fligenspan (2008) analisou as exportações de quarenta e oito setores entre 
1999 e 2005. O autor considerou a demanda doméstica, a taxa de câmbio real, preços e quantidades internacionais e a própria exportação defasada, além de outras variáveis explicativas. Seus resultados reforçam a característica dinâmica das vendas ao exterior, em que a exportação presente é influenciada pela exportação passada. Além disso, corroboram a relação inversa entre a demanda doméstica e as exportações. Finalmente, acham evidência de que a taxa de câmbio não influenciou significativamente as vendas externas no período investigado.

Santos et al. (2009) calcularam as elasticidades preço e renda das exportações e das importações em um painel de estados brasileiros e, em linha com Fligenspan (2008), encontraram valores de elasticidades menores no modelo dinâmico do que nos modelos estáticos de efeitos fixos e de efeitos aleatórios. O período de estudo considerado situou-se entre 1992 e 2007, capturando, portanto, diferentes regimes cambiais. As variáveis exportação e importação foram consideradas em valores deflacionados, respectivamente, pelo índice de preço da Funcex e pelo índice de preço no atacado dos EUA. Pela especificação dos autores, as elasticidades preço são aquelas associadas à variável taxa de câmbio real, e não a algum índice de preços.

No trabalho de Campos \& Arienti (2002), os valores das elasticidades renda das exportações e das importações foram empregados na verificação da validade da lei de Thirlwall para a economia brasileira entre 1980 e 1997. Apesar de concluírem que houve restrição externa ao crescimento no período, dada a elevada elasticidade renda calculada para as importações, a abordagem do modelo de Thirlwall adotada foi a ingênua, no sentido de que consideraram somente os fluxos de capitais oriundos das transações de bens, ignorando outros fluxos financeiros.

Um trabalho clássico de estimação das elasticidades preço e renda do comércio exterior brasileiro é o de Zini Jr. (1988). O autor adotou o modelo de economia pequena para as importações, calculando assim apenas a demanda por importações. Para o caso das exportações, assumiu o modelo de substitutos imperfeitos, e estimou simultaneamente oferta e demanda por exportações através do método 2SLS. Diferentemente dos trabalhos citados acima, o autor empregou os índices de quantum de comércio como variável dependente, ao invés de utilizar seus valores. Seus resultados rejeitam as especificações estáticas em favor das especificações dinâmicas, em linha com os resultados de Thursby \& Thursby (1984).

Neves \& Lelis (2007) desenvolveram um trabalho com o objetivo de estimar as elasticidades preço e renda das exportações dos estados brasileiros. Dentre outros foram utilizados dados do Ministério do Desenvolvimento, Indústria e Comércio Exterior, da FUNCEX, do Núcleo de Conjuntura do Instituto de Economia da UFRJ e da Fundação Getúlio Vargas. A partir de um sistema de equações de oferta e de demanda, foram realizados exercícios econométricos visando calcular as elasticidades preço e renda dos estados 
brasileiros, considerando dados de 1992 a 2004. Os resultados apontam para um comportamento variado das exportações brasileiras, passando de uma relativa estabilidade nos primeiros anos de análise para um período de queda e posterior recuperação expressiva, suportada por produtos de menor valor agregado, sobretudo após a desvalorização cambial ocorrida em 1999. No que tange aos estados, apenas São Paulo, com maior participação de produtos manufaturados em suas exportações, apresentou dinâmica diferente das demais regiões do país que apresentaram participação diferenciada de manufaturados na pauta de exportação. Por fim, o trabalho destaca que as exportações seguiram a tendência das importações mundiais e foi possível constatar uma resposta elástica à dinâmica da renda mundial, ficando evidente, em uma visão desagregada, a influência decisiva do estado de São Paulo, sobretudo em função de sua pauta de exportação incluir produtos de demanda crescente no comércio mundial.

O trabalho de Skiendziel (2008) buscou, por meio de métodos econométricos, estimar as elasticidades de oferta e de demanda das funções de importação e de exportação para o Brasil. Para tanto, foram realizadas estimativas de equações de oferta e de demanda do país e do resto do mundo para o curto e o longo prazos utilizando, para os anos de taxa de câmbio flexível, o método generalizado de momentos sobre os dados trimestrais de comércio, além de estimativas como a da taxa de câmbio de equilíbrio. Os resultados para o Brasil foram bem comportados, ou seja, aderentes ao disposto na teoria. No que tange às elasticidades-renda, em geral, foram encontrados valores superiores à unidade para o curto e o longo prazos, com exceção da oferta estrangeira de exportações que se assumiu, por hipótese, igual à unidade. $\mathrm{O}$ trabalho ainda avançou na estimação das elasticidades de oferta e de demanda de divisas, com a qual foi possível realizar cálculos das elasticidades da balança comercial para o período de 1991 a 2007, bem como verificar a condição clássica de Marshall-Lerner.

Schettini et al. (2011), a partir de dados agregados das Contas Nacionais Trimestrais, desenvolveram um trabalho visando estimar uma função para as exportações brasileiras, utilizando novas especificações econométricas, que considerasse possíveis não linearidades, compreendendo dados de 1995 a 2009. O trabalho utilizou modelos uniequacionais e buscou estimar uma forma reduzida para as exportações, considerando como variáveis explicativas a renda mundial e a taxa de câmbio real. Seus resultados apontam para uma variação não significativa das elasticidades e para um multiplicador da taxa de câmbio real pequeno. No que tange à dinâmica de curto prazo, pode-se observar uma influência não desprezível da renda mundial e um impacto não significante da taxa de câmbio.

De maneira geral, os trabalhos apontam consistentemente para o comportamento dinâmico tanto das exportações quanto das importações. Além disso, as elasticidades renda e preço tendem a ser maiores quando contemplados 
por uma especificação estática. Nesse sentido, existem evidências de que as avaliações empíricas devem levar em consideração modelos dinâmicos em suas estimações. Em geral, no entanto, as elasticidades estimadas são muito sensíveis às especificações, às técnicas econométricas adotadas, ao tratamento dos dados, ao período utilizado e à escolha das proxies para renda e para preços. Isso sugere que a evolução do comércio exterior brasileiro ao longo do tempo não segue um determinado padrão, de forma que ainda há espaço na literatura para tentativas adicionais de se estimar mais precisamente seus determinantes.

\section{Evolução recente do comércio internacional brasileiro}

O comércio exterior brasileiro desenvolveu-se a taxas expressivas entre 2003 e 2010, com exportações e importações crescendo em média cerca de $20 \%$ ao ano, apesar da queda ocorrida durante a crise mundial de 2008-2009. Diversos fatores explicam essa evolução, como o crescimento expressivo da economia mundial até 2008, a entrada da China na OMC, as medidas simplificadoras adotadas na área cambial, entre outras explicações. Maiores detalhamentos do processo de crescimento da inserção brasileira no comércio internacional fogem do escopo deste trabalho, porém cabe destacar que, apesar da recente evolução das vendas externas de produtos extrativistas, a indústria de transformação possui papel de destaque no período investigado.

Dentre os produtos importados, destacam-se aqueles da indústria de transformação, representando em média $85 \%$ do valor total das importações. Em seguida, encontram-se os produtos da indústria extrativa, representando em média 13\% do total importado entre 2003 e 2010. Apesar de ligeiramente inferior em importância, a indústria de transformação permanece como destaque dentre as exportações, representando em média $77 \%$ do valor exportado no período. A indústria extrativista vem em seguida com 14\% do total. Assim, dada a importância da indústria de transformação sobre os totais dos valores importados e exportados, justifica-se o foco adotado na análise deste trabalho. Os gráficos 1 e 2 abaixo apresentam a evolução dos valores exportados e importados nos principais segmentos industriais. 
GRÁFICO 1. EVOLUÇÃO DAS EXPORTAÇÕES BRASILEIRAS (US\$ MILHÃO) - 2003 A 2010

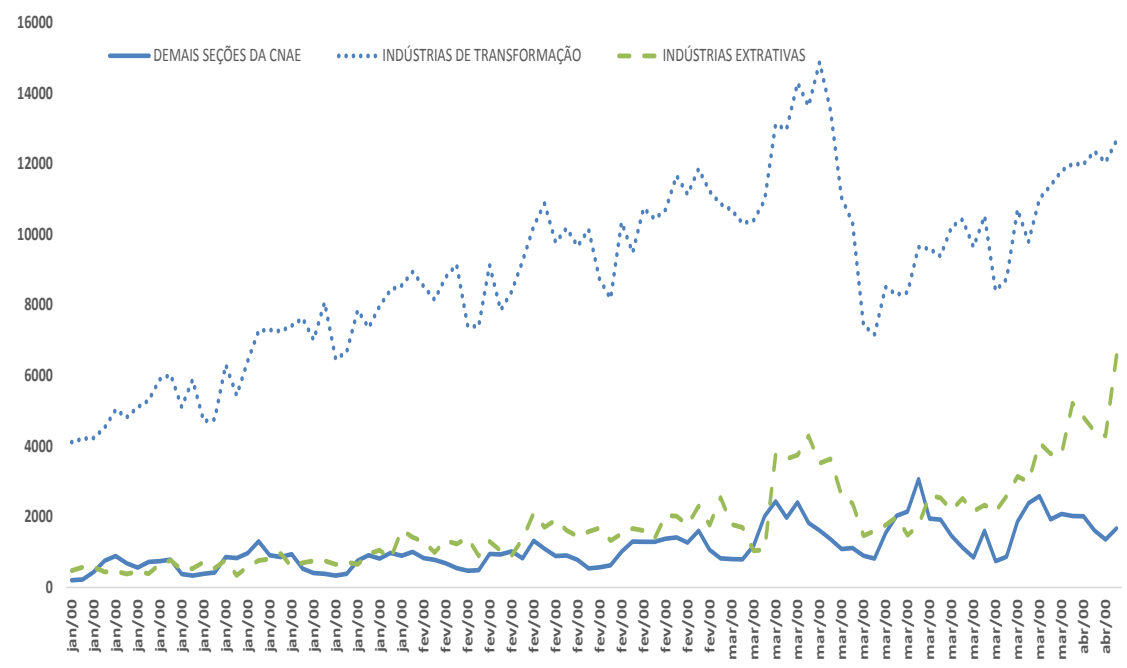

Fonte: Sistema Aliceweb - MDIC

GRÁFICO 2. EVOLUÇÃO DAS IMPORTAÇÕES BRASILIEIRAS (US\$ MILHÃO) - 2003 A 2010

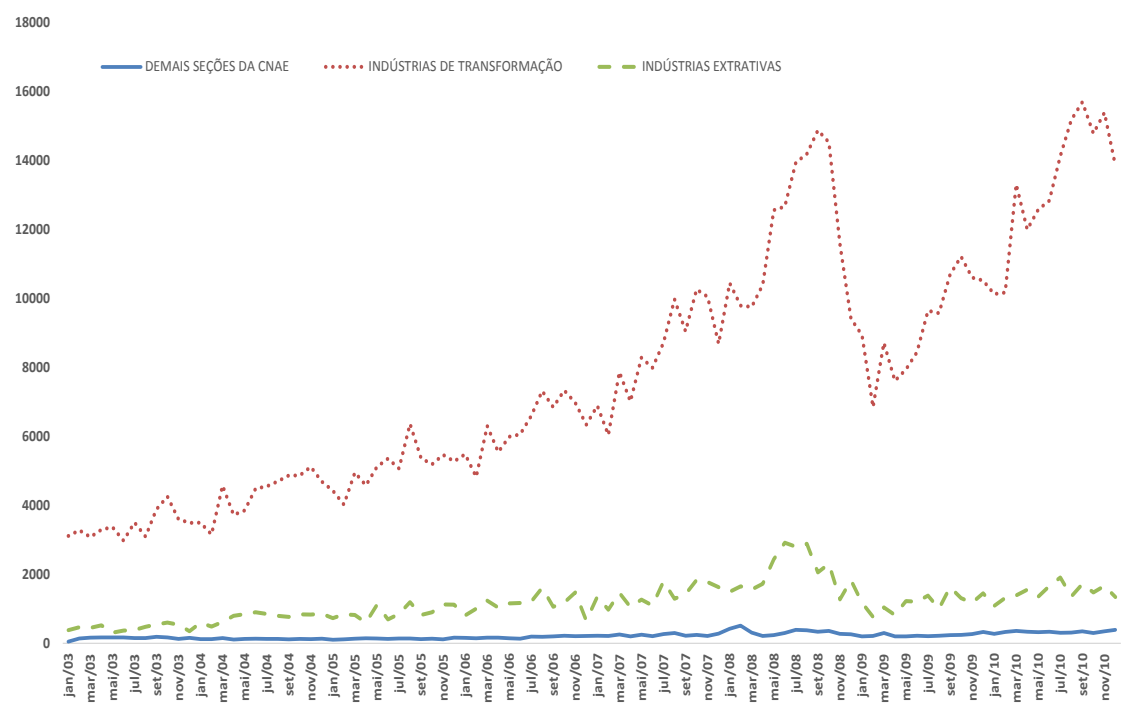

Fonte: Sistema Aliceweb - MDIC 
Dentre os produtos da indústria de transformação, os destaques na importação no período avaliado são produtos químicos, equipamentos de informática, máquinas e equipamentos e veículos, com participações médias nos valores totais do período de $19,5 \%, 17 \%, 12,2 \%$ e $10 \%$, respectivamente. Nas exportações, os destaques são produtos alimentícios, metalurgia, veículos e produtos químicos, com participações médias nos valores totais do período de $23 \%$, $13,4 \%, 12,3 \%$ e $6,7 \%$, respectivamente.

Apesar de haver maior concentração de produtos nas vendas ao exterior, em detrimento às compras, entende-se que há diversificação suficiente para se justificar o modelo de economia pequena discutido anteriormente.

\section{Dados e Modelo Econométrico}

Os dados mensais de comércio exterior foram obtidos no sistema Aliceweb do Ministério do Desenvolvimento, Indústria e Comércio, sendo as informações de peso e de valor de cada Nomenclatura Comum do Mercosul (NCM) agregadas por códigos $\mathrm{CNAE}^{4}$. Como o interesse do presente trabalho recai apenas sobre os produtos industrializados, considerou-se exclusivamente a seção da indústria de transformação $0^{5}$. Essa seção está dividida em 23 categorias. No entanto, três dessas categorias não apresentam produtos que foram comercializados externamente de maneira regular ou com valores significativos ${ }^{6}$. Dessa maneira, a base de dados apresenta os índices de quantum e de preços para 20 categorias da indústria de transformação. O tempo de análise compreendeu janeiro de 2003 a dezembro de 2010, totalizando 96 períodos, escolhidos em função da disponibilidade de dados. Os dados da proxy utilizada para renda interna, a Produção Industrial Mensal, só estão disponíveis a partir de 2003.

\subsection{Importação}

Para o caso das importações, dada a pulverização das compras brasileiras em diversos produtos e países, supõe-se o modelo de economia pequena, investigando-se apenas a demanda por importados. Seguindo Hong (1999), para quem as variáveis de renda e de preço seriam suficientes para capturar a maior parte das variações no comércio exterior de um determinado país, e buscando a parcimônia, foram introduzidas como variáveis explicativas apenas a renda nacional e duas variáveis que captam a mudança nos preços

\footnotetext{
4 Foi utilizada a versão 1.o dessa classificação. Apesar de essa classificação não estar mais em vigor, ela foi empregada por ser adotada pela Fundação Centro de Estudos do Comércio Exterior (Funcex), que foi a fonte primária dos índices de quantum e de preço das exportações e das importações.

5 A indústria de transformação compreende as atividades que envolvem a transformação física, química ou biológica de materiais, substâncias ou componentes com a finalidade de se obterem produtos novos. Não estão incluídos na análise, portanto, produtos oriundos das indústrias extrativas, como minerais, carvão e petróleo, por exemplo.

6 São elas: fabricação de produtos do fumo; edição, impressão e reprodução de gravações; e reciclagem.
} 
relativos: o próprio índice de preços das importações e a taxa de câmbio. Assim, estimou-se a seguinte equação:

$$
\ln Q_{i, t}^{M D}=\beta_{0}+\beta_{1} \ln Y_{i, t}+\beta_{2} \ln P_{i, t}^{M}+\beta_{3} \ln E_{t}+\beta_{4} \ln D U_{t}+\alpha_{i}+u_{i, t}^{M D}(1)
$$

em que cada subscrito $t$ refere-se a um mês e cada subscrito $i$ a um divisão de atividade da CNAE 1.o. O termo $\alpha_{i}$ captura as características invariantes de cada setor e $u_{i, t}^{M D}$ são os erros independentes e identicamente distribuídos. A variável dependente $Q_{i, t}^{M D}$ é o índice de quantum das importações brasileiras. A variável $Y_{i, t}$ é o índice de produção industrial mensal (PIM-PF), calculado pelo IBGE, que foi utilizado como proxy para a renda nacional. A opção por essa variável se justifica por ela permitir construir uma série para cada categoria da indústria de transformação, diferentemente do que ocorreria se o PIB fosse utilizado. Espera-se uma relação positiva dessa variável com a importação, na medida em que um aumento da renda doméstica está associado a um incremento na demanda por importados. Seguindo a recomendação de Zini Jr. (1988), para quem a utilização de variáveis compostas não é recomendada por obscurecer os impactos diferenciados de cada variável isolada, utilizam-se duas variáveis para capturar o efeito preço na demanda por produtos importados. A variável $P_{i, t}^{M}$ representa o índice de preço das importações fornecido pela Funcex. A variável $E_{t}$ é a taxa de câmbio nominal em final de período, posição de venda, divulgada pelo Banco Central do Brasil7. Espera-se uma relação inversa entre ambas as variáveis e a demanda por importados. Como se está trabalhando com quantidades importadas mensais, o número de dias úteis no mês pode influenciar nessa quantidade. A variável $D U_{t}$ foi introduzida para controlar esse efeito ${ }^{8}$.

\subsection{Exportação}

Como as exportações brasileiras são relativamente concentradas, pensou-se inicialmente em estimar as equações de demanda e de oferta separadamente. Porém, como os dados amostrais deste trabalho são exclusivamente da indústria de transformação, e as concentrações de exportações brasileiras

\footnotetext{
7 Dois motivos pesaram para a decisão de se utilizar a taxa de câmbio nominal, em detrimento da real, nas estimações. Em primeiro lugar, porque se supõe que os empresários tomam suas decisões de importação e de exportação com base na variável que é observável, no caso a taxa de cambo nominal. Em segundo lugar, os dados de taxa de câmbio efetiva real, calculada pelo IPEA como uma média ponderada da paridade do poder de compra dos 15 maiores parceiros comerciais em cada setor, não estava disponível para os últimos três meses de 2010, o que implicaria na perda de 60 observações. De qualquer maneira, todos os modelos também foram estimados utilizando a taxa de câmbio real no lugar da taxa de câmbio nominal. Os resultados não se modificaram, em termos de sinal e de significância dos coeficientes estimados.

8 Alternativamente, se poderia dessazonalizar as séries para eliminar os efeitos específicos de cada mês sobre as quantidades importadas e exportadas. Contudo, essa abordagem foi preterida a fim de não se correr o risco de se eliminar alguma variação importante para a explicação dos determinantes das importações e das exportações. De qualquer forma, estimou-se modelos utilizando séries dessazonalizadas. Os resultados não foram sensíveis a essas especificações.
} 
ocorrem em produtos da indústria extrativa e da agropecuária, decidiu-se pela suposição de economia pequena, investigando-se apenas a demanda por exportados. Seguindo os mesmos princípios que nortearam a escolha da especificação para a função demanda por importações, estimou-se a seguinte equação:

$$
\ln Q_{i, t}^{X D}=\beta_{0}+\beta_{1} \ln Y_{i, t}^{F}+\beta_{2} \ln P_{i, t}^{X}+\beta_{3} \ln E_{t}+\beta_{4} D U_{t}+\alpha_{i}+u_{i, t}^{X D}(2)
$$

em que, como na equação (1), cada subscrito $t$ refere-se a um mês e cada subscrito $i$ a uma divisão da indústria de transformação na CNAE 1.o. A variável $Q_{i, t}^{X D}$ é o índice de quantum das exportações brasileiras, fornecido pela Funcex; o termo $\alpha_{i}$ captura as características invariantes de cada setor; $u_{i, t}^{X D}$ são os erros independentes e identicamente distribuídos; e $D U_{t}$ corresponde ao número de dias úteis em cada mês. A variável $Y_{i, t}^{F}$ é uma proxy da renda externa, comum a todos os setores e composta pelos índices de produção industrial dos Estados Unidos, Japão, Canadá, México, Reino Unido, França, Itália e Coréia do Sul, ponderado pela participação desses países nas exportações brasileiras em cada mês. Espera-se uma relação positiva dessa variável com as exportações. A variável $P_{i, t}^{X}$ representa o índice de preços das exportações calculado pela Funcex. Espera-se que seu coeficiente seja negativo. Já o coeficiente vinculado à taxa de câmbio nominal, $E_{t}$, deve ser positivo.

As estimações dos parâmetros das equações (1) e (2) foram realizadas inicialmente por Mínimos Quadrados Ordinários, empilhando os dados (POLS). Depois disso, foram utilizados os estimadores de efeitos aleatórios e de efeitos fixos para dados em painel.

Além desses estimadores para modelos cujas variáveis explicativas são consideradas estritamente exógenas, também foram utilizados estimadores para modelos dinâmicos. Seguindo Thursby \& Thursby (1984), Zini Jr. (1988), Fligenspan (2008) e Santos et al. (2009), foram incluídas as variáveis defasadas $Q^{M D}{ }_{i, t-1}$ e $Q^{X D}{ }_{i, t-1}$ no lado direito das equações (1) e (2), respectivamente, constituindo painéis dinâmicos. Sendo as estimações por MQO inconsistentes sob essa nova configuração, uma vez que os termos defasados e os erros são correlacionados, estimou-se os parâmetros das duas equações pelo Método Generalizado de Momentos (GMM). Utilizou-se tanto o estimador de Arellano \& Bond (1991), quanto o de Arellano \& Bover (1995) / Blundell \& Bond (1998). Em ambos os casos, criou-se um instrumento para cada variável e defasagem, ao invés de um instrumento para cada período de tempo, variável e defasagem, como usualmente é realizado. Essa decisão teve como objetivo restringir o potencial problema de excesso de instrumentos decorrente do elevado número de períodos de tempo na amostra selecionada. Pelo mesmo motivo, optou-se 
por não incluir dummies de tempo nos modelos9. Os resultados reportados referem-se à estimação em um estágio ${ }^{10}$.

Contudo, as propriedades assintóticas dos estimadores de Arellano \& Bond (1991) e de Arellano \& Bover (1995) / Blundell \& Bond (1998) ficam comprometidas em amostras com elevados números de períodos e baixo número de indivíduos, em virtude das distorções causadas pela utilização de um grande número de instrumentos (Roodman 2006). Por essa razão, recorreu-se ao modelo de Bruno (2004 e 2005). Esse modelo corrige o viés e a imprecisão de estimadores que utilizam o método de momentos generalizados em amostras com reduzido número de indivíduos por meio de um estimador do tipo LSDV com correção de viés, o qual ele chama LSDVC. Simulações de Monte Carlo em amostras com 10 unidades seccionais e 40 períodos de tempo indicaram um melhor desempenho do estimador LSDVC relativamente aos estimadores de Arellano \& Bond (1991) e de Arellano \& Bover (1995) / Blundell \& Bond (1998) em termos de viés e de raiz do erro médio quadrado (Bruno 2005). Como a proporção entre unidades seccionais e períodos de tempo na amostra selecionada não é muito diferente daquela utilizada nos experimentos de Bruno (2005), acredita-se que o estimador LSDVC produza resultados consistentes.

\section{Resultados}

Os resultados das estimações da função demanda por exportações estão apresentados na tabela 1. Os parâmetros de renda externa e de preço das exportações apresentaram sinais esperados. Todavia, o parâmetro da taxa de câmbio, diferentemente do esperado, foi negativo e significativo para todos os estimadores. Esse resultado indica que a quantidade de exportações de produtos industrializados brasileiros é negativamente relacionada com a taxa de câmbio nominal. Ou seja, uma apreciação cambial aumentaria a quantidade exportada de produtos da indústria de transformação. Esse é um resultado contra-intuitivo, sendo difícil formular alguma hipótese que o sustente. De qualquer forma, essa tarefa foge aos objetivos do presente trabalho, sendo, contudo, interessante tópico para investigação futura.

A presença de correlação serial nos resíduos da regressão por POLS é evidência de presença das características invariantes de cada setor, o que torna essa especificação inválida. O teste de Hausman não rejeitou a hipótese nula de diferença não sistemática entre os coeficientes estimados por efeitos fixos e por efeitos aleatórios. Esse resultado é evidência de ausência de correlação

9 Nos modelos estáticos em painel também não foram incluídas dummies de tempo, em virtude do elevado número de períodos na amostra selecionada. Além disso, a inclusão do número de dias úteis no mês como regressor é capaz de capturar, pelo menos parcialmente, os efeitos específicos de cada mês. Mesmo assim, foram estimados modelos com a inclusão das dummies de tempo em todas as especificações testadas. Em geral, a presença das dummies não permitiu a estimação de pelo menos um dos coeficientes de interesse, em virtude de problemas de colinearidade.

10 Os resultados não são sensíveis às estimações em dois estágios. 
entre a heterogeneidade não observada e as variáveis explicativas, o que aponta para a utilização do estimador de efeitos aleatórios nos modelos estáticos.

A estimação do modelo com a defasagem da variável dependente como regressor por Arellano \& Bond (1991) e por Arellano \& Bover (1995) / Blundell \& Bond (1998) utilizou, como esperado, um número muito elevado de instrumentos relativamente ao número de unidades cross-section. Isso corrompe a propriedade assintótica dos estimadores e enfraquece os testes de Sargan/ Hansen, que passam a não ser confiáveis (Roodman 2006; e Roodman 2008). Espera-se que o estimador LSDVC corrija o viés presente nesses estimadores. Como a defasagem da variável dependente consegue explicar boa parte da sua variação contemporânea ${ }^{11}$, as elasticidades das exportações brasileiras de produtos industrializadas estimadas pelo presente trabalho são aquelas apresentadas na coluna (6) da tabela $1^{12}$.

Por esses valores, um aumento de $10 \%$ na quantidade exportada hoje irá aumentar a quantidade exportada em $6,1 \%$ no período seguinte. Já um aumento de $10 \%$ na renda externa, irá aumentar em $7,7 \%$ a quantidade exportada. Um aumento de $10 \%$ nos preços dos produtos exportados irá diminuir a quantidade vendida ao exterior em $2 \%$. Tem-se ainda o resultado contra-intuitivo, como já mencionado, de que uma desvalorização de $10 \%$ irá diminuir a quantidade exportada em 1,4\%. Pelas magnitudes dos coeficientes, percebe-se que as exportações de produtos industrializados são muito mais sensíveis a variações na renda que nos preços. Pode-se ressaltar ainda a importância da introdução do termo dinâmico nas estimações, que acaba diminuindo significativamente a magnitude das elasticidades estimadas nos modelos estáticos.

Os resultados das estimações da demanda brasileira por produtos industrializados importados são apresentados na tabela 2. Como no caso das importações, foi detectada correlação serial nos resíduos da regressão por POLS. Logo, devem-se utilizar especificações que levem em consideração as características invariantes de cada setor. A não rejeição da hipótese nula no teste de Hausman também indica preferência pela utilização do estimador de efeitos aleatórios em especificações sem um componente dinâmico. Nessa especificação, os parâmetros referentes à renda e à taxa de câmbio apresentam o sinal esperado. Já o parâmetro referente aos preços de importação não é significativamente diferente de zero.

Contudo, como no caso das exportações, há evidências de existência de persistência nas quantidades importadas. Por essa razão, estimaram-se modelos dinâmicos por meio dos estimadores de Arellano \& Bond (1991) e de Arellano \& Bover (1995) / Blundell \& Bond (1998). Da mesma forma que nas exportações, o elevado número de períodos de tempo na amostra selecionada forçou

11 Conforme defendido por Zini Jr. (1988), Fligenspan (2008) e Santos et al. (2009). A significância estatística do índice de quantidade defasado nas especificações dinâmicas corrobora essa hipótese.

12 Como os coeficientes estimados nas colunas (6) e (7) são aproximadamente iguais, é indiferente a utilização dos valores de uma ou de outra coluna. 
a utilização de muitos instrumentos nas estimações, produzindo, portanto, estimativas pouco confiáveis. Espera-se que o procedimento LSDVC corrija o viés desses estimadores. Nesse sentido, as elasticidades das importações brasileiras de produtos industrializadas estimadas pelo presente trabalho são aquelas apresentadas na coluna (6) da tabela 2.

Os sinais das variáveis relevantes se comportam de acordo com o esperado. A resposta do montante importado a variações na renda interna é maior que a resposta a variações nos preços dos produtos. Contudo, a maior resposta advém de variações na taxa de câmbio nominal. Espera-se que um aumento de $10 \%$ na taxa de câmbio diminua a quantidade de produtos industrializados importados em $4,3 \%$, em média. A presença da defasagem da quantidade importada se mostrou estatisticamente significante e relevante em termos de grandeza. A sua presença fez com que os coeficientes da renda, dos preços e da taxa de câmbio diminuíssem sua magnitude, quando comparados com a estimação por efeitos aleatórios.

Comparando os coeficientes da taxa de câmbio das equações de exportação e de importação, tem-se que uma desvalorização cambial reduz tanto a quantidade exportada quanto a quantidade importada de produtos industrializados. Todavia, esse efeito é cerca de três vezes maior sobre as importações. Nesse sentido, desvalorizações cambiais devem levar a uma melhora nos termos de troca do comércio exterior de produtos industrializados no Brasil. Esse resultado relativiza um pouco o resultado contra-intuitivo de queda das exportações a partir de uma desvalorização cambial. 
KAWAMOTO, C. T.; SANTANA, B. L.; FONSECA, H. Elasticidade Renda e Elasticidade Preço...




KAWAMOTO, C. T.; SANTANA, B. L.; FONSECA, H. Elasticidade Renda e Elasticidade Preço...

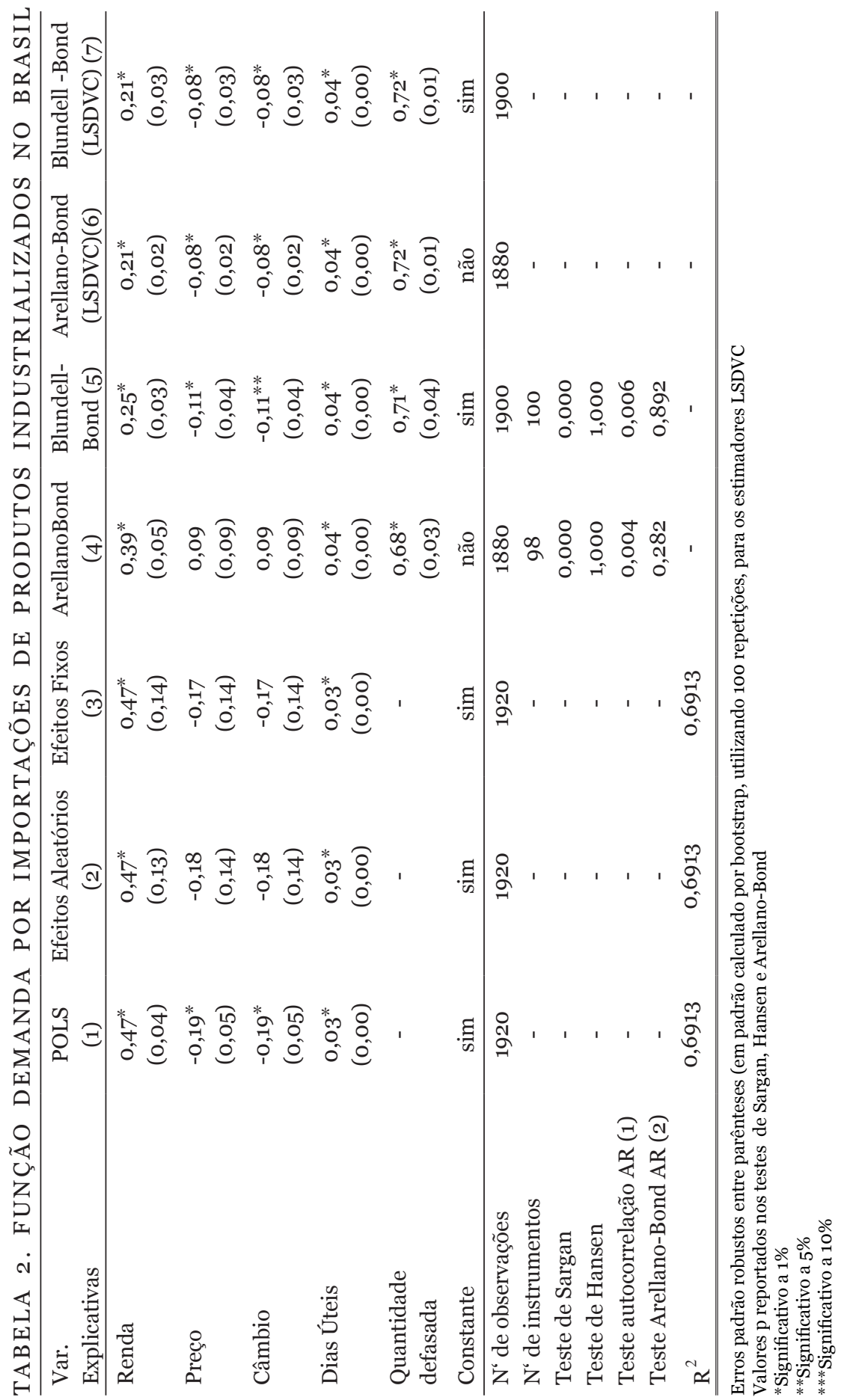




\section{Considerações Finais}

O presente trabalho teve como objetivo principal estimar as elasticidades renda e preço das exportações e das importações de produtos industrializados no Brasil. A sua principal contribuição é a estimação dessas elasticidades exclusivamente para o setor da indústria de transformação brasileira. Esse tipo de análise não é muito comum na literatura. Nesse sentido, apesar de as elasticidades aqui estimadas estarem, em geral, dentro da amplitude de valores encontrados nessa literatura, elas não são diretamente comparáveis com as elasticidades estimadas para os valores agregados do comércio exterior brasileiro. Apesar disso, destaca-se o resultado encontrado de que eventuais controles de déficits comerciais são mais efetivos se tomados pela demanda agregada e não pelo câmbio, diferentemente do apontado por Castro \& Cavalcanti (1998).

O trabalho traz evidências adicionais da importância de se incorporar elementos dinâmicos na especificação econométrica em exercícios de estimação de elasticidades para o comércio exterior em geral. Em particular, as exportações e as importações de produtos da indústria de transformação se mostraram mais sensíveis a variações na renda que a variações nos preços. Além disso, variações na taxa de câmbio tiveram o efeito esperado sobre a balança comercial dos produtos industrializados no país, em que pese o efeito negativo contra-intuitivo apresentado na função demanda por exportações. A esse respeito, existe espaço para investigações futuras que busquem elementos que ajudem a entender esse resultado.

Finalmente, a utilização de métodos econométricos alternativos, como o estimador LSDVC aqui utilizado, recomendados a situações mais particulares que aquelas em que os estimadores para dados em painel mais usuais são recorrentemente utilizados, podem dar um novo prisma e contribuir para uma definição mais robusta de parâmetros exaustivamente já estimados na literatura empírica sobre as elasticidades do comércio exterior brasileiro.

\section{Referências}

ARELLANO, M.; BOND, S. (1991). "Some tests of specification for panel data: Monte Carlo evidence and an application to employment equations." Review of Economic Studies 58 (2): 277-97.

ARELLANO, M.; BOVER, O. (1995). "Another look at the instrumental variables estimation of errorcomponents models." Journal of Econometrics 68 (1): 29-51.

BLUNDELL, R.; BOND, S. (1998). "Initial conditions and moment restrictions in dynamic panel data models." Journal of Econometrics 87 (1): 111-43.

BRUNO, G. (2004). "Approximating the bias of the LSDV estimator for dynamic unbalanced panel data models." CESPRI Working Paper, n.159. 
BRUNO, G. (2005). "Estimation and inference in dynamic unbalanced panel data models with a small number of individual.” CESPRI Working Paper, n.165.

CAMPOS, A. C.; ARIENTI, P. (2002). “A importância das elasticidades-renda das importações e das exportações para o crescimento econômico: uma aplicação do Modelo de Thirlwall ao caso brasileiro.” Ensaios FEE 23 (2): 787-804.

CASTRO, A.; CAVAlCANTI, M. A. (1998). "Estimação de Equações de Exportação e Importação para o Brasil - 1955/95.” Pesquisa e Planejamento Econômico 28 (1): 1-68.

FLIGENSPAN, F. B. (2008). “As exportações da indústria brasileira pós-desvalorização cambial de 1999.” In: XXXVI Encontro Nacional da ANPEC, 2008, Salvador. Anais do XXXVI Encontro Nacional da ANPEC. Rio de Janeiro: ANPEC.

FULLERTON, T. M.; SAWYER, W. C..; SPRINKLE, R. L. (1999). "Latin American Trade Elasticities.” Journal of Economics and Finance 23 (1): 143-156.

HONG, P. (1999). “Import Elasticities Revisited.” New York: United Nations - Economic \& Social Affairs, DESA Discussion Paper $\mathrm{n}^{\mathrm{0}} 10$.

NEVES, A. C. P. ; LÉLIS, M. T. C. (2007). "Exportações estaduais no Brasil: estimativas para as elasticidades preço e renda.” Revista de Economia Política 27 (2): 102-135.

ROODMAN, D. (2006). "How to do xtabond2: an introduction to 'difference' and 'system' GMM in Stata.” Center for Global Development Working Paper, n.103.

ROODMAN, D. (2008). “A Note on the Theme of Too Many Instruments.” Center for Global Development Working Paper, n.125.

SANTOS, A. M.; SOUSA, E. A.; TEJADA, C. A.; JACINTO, P. A. (2009). "Elasticidades Preço e Renda das Exportações e Importações: uma Abordagem Através de Dados de Painel para os Estados do Brasil.” In: VII ENABER - Encontro Nacional da Associação Brasileira de Estudos Regionais e Urbanos, São Paulo.

SCHETTINI, B. P.; SQUEFF, G. C.; GOUVÊA, R. R. (2011). "Estimativas da Função de Exportações Brasileiras Agregadas com Dados das Contas Nacionais Trimestrais (1995 - 2009).” Texto para Discussão n ${ }^{0} 1598$. Instituto de Pesquisa Econômico Aplicada - IPEA. Brasília.

SKIENDZIEL, A. G.L. (2008). "Estimativas de Elasticidades de Oferta e Demanda de Exportações e de Importações Brasileiras.” Brasília: dissertação de Mestrado. Universidade de Brasília - Instituto de Ciências Humanas.

THIRLWALLA. P. (1979). "The balance of payments constraint as an explanation of international growth rates differences." Banca Nazionale del Lavoro Quarterly Review 128 (1): 45-53.

THURSBY, J.; THURSBY, M. (1984). "How Reliable are Simple, Single Equation Specifications of Import Demand?” The Review of Economics and Statistics 66 (1): 120-128.

USDA - United States Department of Agriculture. (2011). "World Agricultural Supply and Demand Estimates." Office of the Chief Economist. August.

ZINI JR, Á. A. (1988). “Funções de exportação e de importação para o Brasil.” Pesquisa e Planejamento Econômico 18 (3): 615-662. 
KAWAMOTO, C. T.; SANTANA, B. L.; FONSECA, H. Elasticidade Renda e Elasticidade Preço...

Recebido em: o8 de janeiro de 2013

Aceito em : 04 de outubro de 2013 
